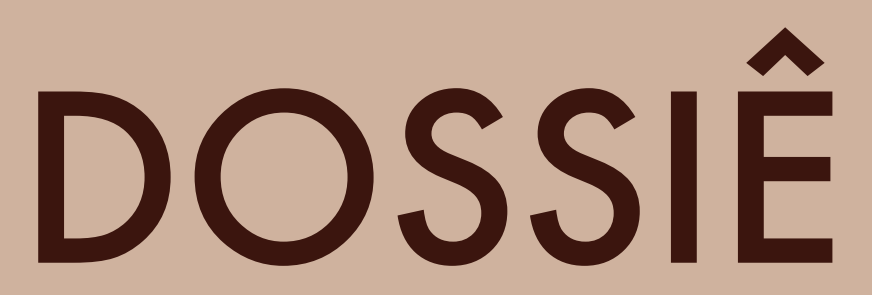

FOLHAS SECAS: MEMÓRIA POLITIICA DA FLORESTA ORGANIZACCÃO: ANA CAROLINA PRUDENTE NASCIMENTO E AUGUSTO MELO BRANDÃO 


\title{
QUANDO PISO EM FOLHAS SECAS...
}

\section{> Ana Carolina Prudente Nascimento [Universidade Federal Fluminense, Brasil] *} Augusto Melo Brandão [Universidade Federal Fluminense, Brasil] * *

hitps://doi.org/10.22409/poiesis.v22i38.50693

\author{
errando, errando - \\ Apátria, Exlândia, Des- \\ terra, há anos: esse Estado, \\ teu estado, de estar \\ em-viagem. \\ Em viagem, Age de Carvalho
}

Lianas abraçarão na curva do rio

a insónia dos mortos

quando a primeira mulher

lavar as tranças no leito ressuscitado.

Reabitaremos a casa, nossa intacta morada.

Sóya, Conceição Lima

\footnotetext{
* Ana Carolina Prudente Nascimento é psicóloga, psicanalista e mestranda em Estudos Contemporâneos das Artes pela Universidade Federal Fluminense. E-mail: anacpru@outlook.com, ORCID: https://orcid.org/0000-0002-9946-3210

* * Augusto Melo Brandão é mestrando em Estudos Contemporâneos das Artes pela Universidade Federal Fluminense, performer, escritor, tarólogo e astrólogo. E-mail: cartas.m.b.a@gmail.com, ORCID: https://orcid.org/0000-0003-1894-634X 
Pisar em folhas secas: gesto de colocar as memórias para que tomem sol. Derretendo como a pele dos velhos, as folhas vão aos poucos caindo das copas. Vingativas, forçam a memória à custa de seu próprio fim, quando pressionadas pela sola calejada dos pés, estalam. Mas... de que pés? Dos pés do sambista Nelson Cavaquinho [1973], por exemplo, que de tanto subir e cantar o morro da Mangueira sob o calor quente do sol, vai aos poucos se acabando até que, um dia, não reste mais que folhas secas, saudades de sua mocidade. Ao escutar o samba que dá o título deste dossiê, o ouvinte menos empático poderia argumentar que enquanto o sambista acaba pouco a pouco - derretido pelo calor do sol, pelo trabalho extenuante e pelo sobe-e-desce diário morro-asfalto - haverá sempre outras folhas e mangas para cair de cima, sustentadas pela seiva que une as raízes aos frutos, os jovens aos anciãos.

Não é o que tem acontecido, entanto, por essas paragens. Como lembra outro compositor, "o galo já não canta mais no Cantagalo/ a água não corre mais na Cachoeirinha/ menino não pega mais manga na Mangueira/ e agora que cidade grande é a Rocinha" [PINHEIRO, 2003]. Versos como os de Pinheiro e Cavaquinho parecem revelar que aqui os frutos têm escasseado, e as raízes, quando não arrancadas do solo infértil, já não podem fornecer senão o som seco das folhas. Em um segundo nível, eles nos fazem pensar sobre o que nos permite comungar de um "aqui", desenhar uma topografia capaz de unir o que a violência colonial dividiu segundo os binarismos do morro e do asfalto, da mata e da cidade, do sertão e do litoral, da colônia e da metrópole. Um desenho que só pode ser feito por pés como os de Cavaquinho, pés de poetas, trabalhadores, negros e indígenas, que escutam a cada pisada o barulho ensurdecedor das folhas. Enquanto as árvores queimam, a marcha dissonante desses pés calejados é hoje o tronco que nos resta, nossa esperança de um outro comum que não a morte. Tronco sonoro, porque feito do estalar das folhas secas em revolta, dos cantos de saudade e de fúria em nome daqueles que não querem ir-se daqui. Pela poesia dos nomes da floresta.

"Ivo Azevedo dos Santos, Ribeirinho, Coari-AM, 11/1/2000 / Trabalhador rural desconhecido, Santana do Araguaia-PA, 31/5/2000 / Neuci Barbosa da Silva, Liderança, Parauapebas, 30/5/2000..." - em Memorial Da Terra: AMZ.21, Hugo Nascimento coleta 420 nomes de pessoas - ambientalistas, indígenas, sindicalistas, quilombolas e trabalhadores sem-terra - vítimas diretas dos conflitos fundiários na Amazônia brasileira a partir dos anos 2000. Em meio aos nomes, encontramos fotocópias produzidas através de emulsões fotossensíveis de jenipapo 
e urucum, extraídas e processadas na llha de Caratateua, Belém-PA. Entre revelações e apagamentos, o trabalho parece propor um encontro entre os que já foram e os que ficam, encontro que no lugar de resolver tensões, denuncia fraturas abissais, alertando para o risco de que, no próprio gesto de ver o passado, acabemos por enterrá-lo novamente com as pisadas silenciosas de nossos olhos.

É da dimensão política desse gesto de alerta que desejamos tratar aqui. Folhas secas: memória política da floresta reúne ao todo sete trabalhos que, de diferentes formas, politizam olhares e memórias sobre a Amazônia. São artigos e ensaios visuais que chegaram às nossas mãos durante o processo de elaboração da última edição da Revista Poiésis, marcados por uma mesma urgência: a de denunciar o processo sistemático de destruição da floresta e de apagamento de seus povos, escutando as memórias que habitam as serapilheiras. Nosso abre-alas, Memorial da Terra - AMZ.21 coloca em primeiro plano os limites dessa tarefa, quando nos leva a perguntar: diante de 420 nomes, o que podem as imagens? Formulando de outro modo: o que significa olhar as sucessivas cenas de biomas em chamas, lideranças indígenas assassinadas, pessoas sufocando em hospitais por falta de oxigênio, chacinas policiais e uma cifra de 500.000 vidas interrompidas?
Se o panóptico moderno destituiu o olhar de sua materialidade - em prol da ficção daquele que tudo vê - encontramos sua evolução nos meios de comunicação e nas redes sociais, com sua miríade de imagens e receitas anestésicas para a [des] mobilização via vigilância. 0 descabimento dessa tragédia faz pensar na compulsão à repetição pontuada por Freud e na cultura dos choques que atrofia a experiência através da exposição continuada ao trauma. Mas também nos leva a questionar a preponderância do estímulo ocular na experiência contemporânea. Nesse sentido, queremos propor ao leitor que pense as imagens e textos a seguir como exercícios de escuta, à procura dos sons das folhas secas. Em meio à aceleração progressiva dos tempos, voltar os ouvidos para o passado - não com o ímpeto arquivístico, mas com o gesto imaginativo da memória e da arte - podendo sugerir ressonâncias que de outro modo passariam despercebidas, oferecendo instrumentos para que, na diferença de nossos pés, possamos marchar juntos e juntas em direção à luta no presente.

É o caso do artigo A Última Aventura de Romy Pocztaruk: uma viagem entre as utopias e ruínas na região amazônica. Nesse ensaio, Rafael Fontes Gaspar retoma a série A última Aventura, em que Pocztaruk percorre quase quatro mil quilômetros da Rodovia Transamazônica, obra faraônica do regime 
militar que, construída sob o argumento de ocupar e integrar a região norte ao restante do território brasileiro, jamais foi concluída. Entre as cidades que a artista atravessa ao longo de seu trajeto, destaca-se Fordlândia, lugar em que Henry Ford construiu em 1927 uma utopia industrial às margens do Rio Tapajós. Entre Transamazônica e Fordlândia, temporalidades diversas se cruzam para desnudar o discurso que, hoje como ontem, enxerga na floresta um território a ser conquistado.

Por um caminho diverso, o artigo de Gil Vieira Costa opera um movimento análogo de pôr em evidência as falências do projeto moderno em perspectiva amazônica. Em Imagens da Amazônia na arte brasileira: do território a conquistar ao território a resistir, o autor mapeia os regimes de visibilidades da Amazônia que perpassaram a arte brasileira desde o início do século XX. É necessário nos atermos aos títulos das quatro primeiras obras que ilustram o trabalho - A conquista do Amazonas, Posse da Amazônia, A conquista da Ama-

O próximo passo foi a Revolução Industrial: o significado da "natureza" em Acosta e Bacon mudou, chegando a se referir a "recursos naturais", o alimento necessário para nutrir as máquinas da Revolução Industrial que produziam outras máquinas [a ferrovia e o automóvel], que, por sua vez, precisavam de mais alimento, carvão e óleo. A "catástrofe ambiental" começou nesse momento. [...] A "natureza" - amplamente concebida - se transformou em "recursos naturais", enquanto a "natureza" - como substantivo concreto que nomeia o mundo físico e não humano - se tornou no Novo Mundo a base para o cultivo de açúcar, tabaco, algodão etc. [MIGNOLO, 2017, p. 7]

Não obstante as sucessivas catástrofes ambientais em mais de 500 anos de empreendimento colonial - presentificadas na forma do projeto político bolsonarista - as ruínas da Transamazônica e de Fordlândia revelam que a floresta resiste às sucessivas investidas da máquina. No contraste entre o sépia das máquinas e o verde da floresta, as imagens de Pocztaruk são para serem vistas ao som de Fora da ordem, de Caetano Veloso: aqui tudo parece que era ainda construção e já é ruína. zônia e As Forças Armadas e a Integração da Amazônia-que representam a ambiguidade fundamental do olhar colonizador e sudestino sobre a floresta e seus povos, ora vistos como "inferno verde", ora como "eldorado paradisíaco". Ao final desse generoso trajeto, o autor nos indaga sobre o futuro: como desconstruir um imaginário em ruínas para criar imagens de uma Amazônia condizente com as aspirações de nosso tempo? [COSTA, 2021]. E nos faz pensar que se a crise de um tempo é marcada pelo recrudescimento das ideologias hegemônicas, o cenário atual é estratégico para a mudança dos paradigmas com os quais pensamos, enxergamos e ouvimos a floresta. 
Ouvir o "grito" de Frans Krajcberg: reverberar sua luta, de Luciana Valio, e As peles de imagem dos sonhos Yanomami, de Joana Mazza, são artigos que reclamam diretamente a urgência de suas questões, destacando em meio ao contexto pandêmico duas trajetórias que puseram suas vidas a serviço da memória política da floresta: Frans Krajcberg e Claudia Andujar. Ambos emigrados de seus países de Krajcberg e Andujar parecem falar, através das distintas materialidades de seus trabalhos, da condição própria do estrangeiro, aquele que, para Julia Kristeva, só pode fixar raízes provisórias aonde encontrar uma paixão - uma luta? - à qual se dedicar. origem por conta da Segunda Guerra Mundial,

Estado, teu estado, de estar em-viagem" [CARVAL$H O, 2017]$, que servem de epígrafe para esse texto, revelam outra sintaxe da estrangeiridade, mais tropical porque mais violenta. A necropolítica impôs aos povos do sul do sul global um estado de desterro em suas próprias terras, materializado na condição indígena, povo cujo território pertence, constitucionalmente, ao Estado. Esse gesto de expropriação continuada - que tem no projeto de lei do marco temporal seu mais novo e funesto capítulo - é todavia mais paradoxal quando percebemos que a "utopia" de uma relação harmônica com o estrangeiro, tal como formulada por Kristeva, não é estranha à episteme Yanomami, cuja diferença em relação aos demais seres - povos - da floresta jamais foi vista sob o signo da separabilidade, mas da contiguidade e da transmutação. Como ressalta Joana Mazza, no contato com os xapi-

Por um lado, a condição nortista parece ressoar os dilemas da estrangeiridade na figura do migrante que parte de sua terra natal em busca de melhores condições de vida, traduzida com maestria na obra do poeta paraense Age de Carvalho. Por outro, os versos "Apátria, Exlândia, Des-/ terra há anos: esse riem seus sonhos comunitários, os Yanomami comungam com os demais seres da floresta, e alertam para os riscos da cobiça ocidental: a queda do céu.

Quando a separabilidade se encontra entranhada em discursos à direita e à esquerda do espectro político, sonhar comunitariamente pode parecer 
uma tarefa impossível. Não é o que percebemos, no entanto, ao nos depararmos com o relato de Leonardo Zenha e Raquel Lopes em Deslocamentos arte-educativos na Transamazônica-Xingu. Nesse artigo, os autores entrelaçam os saberes da arte e da política no interior do Pará, à beira da Transamazônica e dos braços do rio Xingu. Em participação conjunta com o ensino superior local, o trabalho descreve experiências a partir do campo da arte-educação, relatando processos artísticos coletivos que se materializaram em atos políticos na região. 0 trabalho retrata ainda a importância dos decretos de áreas de conservação ambiental dos anos 2000, que refletiram diretamente na garantia de direitos básicos da Constituição Federal de 1988, como a instalação de escolas, apontando a educação como caminho para a construção de uma nova partilha do sensivel a partir das comunidades ribeirinhas.

No pôr do sol, a cigarra voa reto, ensaio visual de Wilka Sales que encerra o Dossiê, aponta que os caminhos para aprender com a floresta podem encontrar-se também na intimidade das memórias familiares. O exercício de autoficção proposto pela artista cruza as linguagens da performance, da fotografia e do vídeo para criar narrativas intemporais a partir de experiências adquiridas por Sales junto das matriarcas de sua família. Em uma série, a autora faz colagens com páginas de uma enciclopédia botânica, folhas e ramagens, questionando o ímpeto arquivístico ocidental através de uma coleta afetiva. Em outro trabalho, reproduz cenas do cotidiano de sua avó, manufaturando as próprias vassouras, urinando de pé ou acendendo lamparinas. Numa espécie de ritual místico, atenta para a performatividade de gênero implicada nos gestos de cuidado do lar, ao mesmo tempo que nos lembra os Yanomamis, que consomem as cinzas de seus ancestrais durante seus ritos fúnebres. Uma das cenas do ensaio mostra um espelho quebrado em uma peneira de vime, o céu e as copas das árvores despedaçados. Partindo de memórias tão pessoais, o trabalho de Sales parece entrever na ancestralidade um portal para o futuro. Como escreve Octavia Butler [2018] em A parábola do semeador. "para ressurgir das próprias cinzas, uma fênix deve primeiro queimar".

Gostaríamos de agradecer aos colaboradores Hugo Nascimento, Gil Vieira Costa, Rafael Fontes Gaspar, Leonardo Zenha, Raquel Lopes, Luciana Benetti Marques Válio, Joana Mazza e Wilka Sales por terem enviado à Revista Poiésis seus trabalhos. Ao Programa de Pós-Graduação em Estudos Contemporâneos das Artes da Universidade Federal Fluminense, em especial ao Professor Luiz Sérgio de Oliveira, pela oportunidade da curadoria e edição do presente Dossiê. Ao brilhante corpo docente do PPGCA-UFF e aos colegas e amigos que fizemos no Mestrado, apesar de todas as distâncias e dificuldades, que sigamos atentos e fortes. 
BUTLER, Octavia. A parábola do semeador. São Paulo: Editora Morro Branco, 2018.

CARVALHO, Age de. Antologia Coleção Postal. Rio de Janeiro: Cozinha Experimental, 2017.

CAVAQUINHO, Nelson. Folhas secas. Rio de Janeiro: Odeon, 1973.

FREUD, Sigmund. Além do princípio do prazer e outros textos [1917-1920]. São Paulo: Companhia das Letras, 2010.

KRISTEVA, Julia. Estrangeiros para nós mesmos. Rio de Janeiro: Rocco, 1994.

LIMA, Conceição. A dolorosa raiz do micondó. São Paulo: Geração Editorial, 2012.

MIGNOLO, Walter. Colonialidade: o lado mais escuro da modernidade. Revista Brasileira de Ciências Sociais, v. 32, n. 94, jun. 2017.

OSBORNE, Peter. Arte contemporânea é arte pós-conceitual. Revista Poiésis, n. 27, p. 39-54, jul./dez. 2016.

PINHEIRO, Paulo César. Nomes de favela. Rio de Janeiro: Quelé, 2003.

SELIGMANN-SILVA, Márcio. A fotografia em Walter Benjamin: a "dialética na imobilidade" e a "segunda técnica". Revista Brasileira de Psicanálise, São Paulo, v. 46, n. 2, p. 121-136, jun. 2012. 